\title{
Designing Transport Policy for Sustainable Freight Movement in Saudi Arabia
}

Hector G. Lopez-Ruiz, Nora N. Nezamuddin and Abdelrahman Muhsen 


\section{About KAPSARC}

The King Abdullah Petroleum Studies and Research Center (KAPSARC) is a non-profit global institution dedicated to independent research into energy economics, policy, technology and the environment across all types of energy. KAPSARC's mandate is to advance the understanding of energy challenges and opportunities facing the world today and tomorrow, through unbiased, independent, and high-caliber research for the benefit of society. KAPSARC is located in Riyadh, Saudi Arabia.

This publication is also available in Arabic.

\section{Legal Notice}

(C) Copyright 2020 King Abdullah Petroleum Studies and Research Center ("KAPSARC"). This Document (and any information, data or materials contained therein) (the "Document") shall not be used without the proper attribution to KAPSARC. The Document shall not be reproduced, in whole or in part, without the written permission of KAPSARC. KAPSARC makes no warranty, representation or undertaking whether expressed or implied, nor does it assume any legal liability, whether direct or indirect, or responsibility for the accuracy, completeness, or usefulness of any information that is contained in the Document. Nothing in the Document constitutes or shall be implied to constitute advice, recommendation or option. The views and opinions expressed in this publication are those of the authors and do not necessarily reflect the official views or position of KAPSARC. 


\section{Key Points}

conomic diversification is a top priority for Saudi Arabia under Saudi Vision 2030, the government's national development masterplan, which sets ambitious targets for the growth of the Kingdom's non-oil industries. This includes making the country a global player in logistics by enhancing the freight transport sector and associated value chain while confronting the related challenges posed by climate change. To achieve this, the government must understand how transport policy measures can contribute to these objectives. Accordingly, this study applies the KAPSARC Transport Analysis Framework to address the heterogeneity of urban, regional and inter-regional areas by analyzing socioeconomic and spatial differences to quantify the likely impacts of different types of policies on fuel consumption, carbon dioxide $\left(\mathrm{CO}_{2}\right)$ emissions, and freight tonnage moved. The key results are highlighted below.

As part of a comprehensive transport infrastructure policy package, the Landbridge is a planned railway that will link Saudi Arabia's west coast with its central region. It will connect to existing rail infrastructure between the central and eastern regions, thus creating a coast-to-coast railway in Saudi Arabia. This would result in an $11 \%$ modal shift from road to rail and a 13\% reduction in fuel consumption by 2030 .

By connecting Makkah Province to the Eastern Province via Riyadh, the Landbridge could reduce the country's fuel consumption by $17 \%$ and $\mathrm{CO}_{2}$ emissions by $19 \%$ if combined with measures to decrease freight transport by road (and thereby increase delivery by rail).

Freight fuel consumption forecast for Saudi Arabia in barrel of oil equivalent (BOE), 2012-2030.

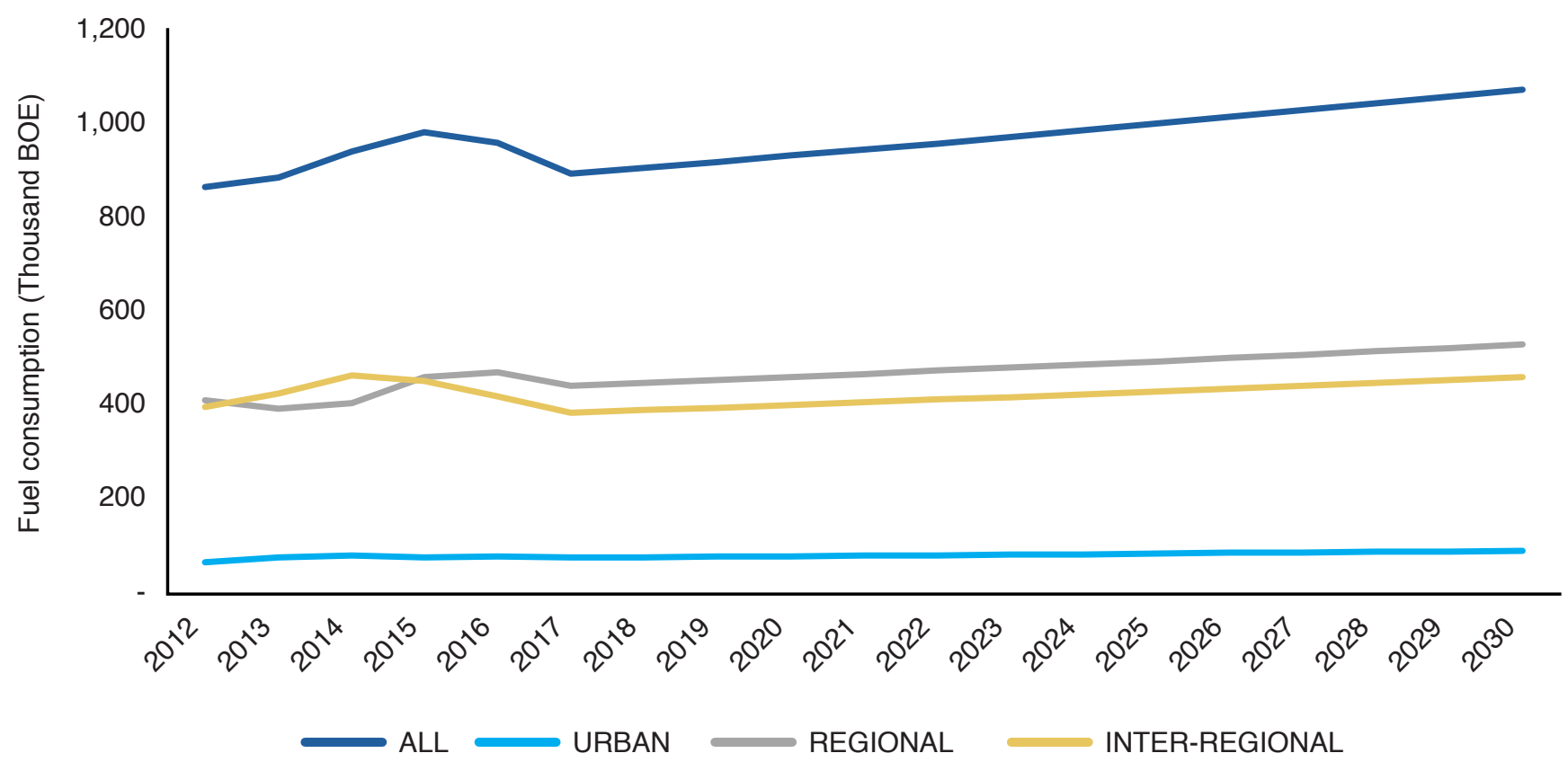

Source: ktaf.kapsarc.org 


\section{Key Points}

Regulations that reduce subsidies on diesel and charge for environmental externalities would raise annual revenue of US\$1 billion, which can help fund infrastructure and transportation projects. This would improve efficiency in Saudi Arabia's freight sector and increase regional connectivity, giving the Kingdom a more central logistics role within the Gulf Cooperation Council region.

A more robust multi-modal freight system will help Saudi Arabia to meet its objectives for the sector by increasing connectivity, security and efficiency. 


\section{Summary}

ogistics and infrastructure policy will play key roles in Saudi Arabia's economic diversification and reform efforts. This study provides a quantitative assessment of specific measures related to freight transport, taking into consideration the heterogeneity of urban, regional and inter-regional localities in Saudi Arabia. This paper, mirroring the global approach developed by the European Commission's Joint Research Centre, analyzes the potential impact of logistics policy. It sheds light on how transport regulations can help rationalize fuel consumption and reduce greenhouse gas emissions and other air pollutants in the Kingdom.

This research utilizes the KAPSARC Transport Analysis Framework (KTAF), an analytic tool for estimating freight transport activity and the impact of transport policy based on open-source data and algorithms. Its methodology follows a number of steps. First, KTAF infers economic and human activity data from nighttime lights satellite images and economic indicators for employment and employment productivity. Second, it analyzes these results using an aggregate four-step transport demand model approach that estimates energy use in transport activity. Finally, the tool employs an avoid-shift-improve approach to assess the likely impact of different policy measures. KTAF portrays the modeling results in an online visual analysis application (ktaf.kasparc.org), which provides a visual representation of the simulation.

The findings of the study showcase the potential effectiveness of measures to increase logistics efficiency, reduce emissions of greenhouse gases and other pollutants, and diminish the consumption of fuel for freight transport activities. The results indicate that Saudi Arabia can achieve the largest reduction in $\mathrm{CO}_{2}$ emissions by combining regulatory and pricing policies with an infrastructure buildout that focuses on increased accessibility to existing major logistical hubs in the Kingdom. Additionally, a more robust multi-modal freight system will reduce road congestion and associated maintenance costs.

Road freight comprises just $20 \%$ of tonne-kilometers shipped globally but consumes $70 \%$ more energy than other modes (IEA 2019). Such inefficiency has major implications for Saudi Arabia, where domestic freight movement depends primarily on the country's road network. Therefore, policymakers require an understanding of how infrastructure development can help the country towards its diversification objectives.

This paper examines two scenarios for freight transport in Saudi Arabia. The first focuses on infrastructure by modeling the successful implementation of the Landbridge, the planned railway project connecting Makkah Province to the Eastern Province via Riyadh. In 2018, Saudi Arabia's Red Sea ports accounted for around $50 \%$ of containerized goods throughput and tonnage in the country; half of this throughput continues overland via Makkah Province to Riyadh Province through roadway connections. The Landbridge would create an $11 \%$ modal shift (based on total freight movement in the country) from road to rail and a $13 \%$ reduction in the country's fuel consumption by 2030 .

The second scenario combines the development of the Landbridge and introduces two policy measures: the removal of diesel subsidies and the introduction of an environmental charge that internalizes a part of the negative externalities linked to freight transport by road. These measures, combined, would generate around US\$1 billion in annual revenue to help cover the capital and operational costs of the Landbridge or other infrastructure development and 
result in a $17 \%$ reduction in fuel consumption a $19 \%$ reduction in emissions by 2030 . They would also help shift the burden of environmental externalities of road transport back onto logistics operators.

In summary, Saudi Arabia's twin objectives of reducing fuel consumption and increasing transport network connectivity call for a combination of infrastructure development and logistics policies. The results of the KTAF analysis offer policymakers an easily digestible visual summary of the potential impacts of relevant measures and can inform their decision-making process. 


\section{Introduction}

o strengthen local economies and counteract negative externalities, many local and national governments around the world have begun to focus on the sustainability of urban and regional transport. The daunting prospect of reorganizing cities and wider urban areas to increase the efficiency of transportation and logistics has generated many questions, including over the best ways to enhance the sustainability - economic, social and environmental - of urban freight transport.

For the logistics sector, the complex relationships between information, costs (capital and operating), behavior, technology, and environmental constraints require policymakers to establish workable normative scenarios. However, these inherently depend on societal and geographical realities. In other words, policies will have varying impacts depending on a city's physical and socioeconomic characteristics, such as population size, built environment, and how the transport system integrates with human and economic activities.

This research aims to provide policymakers with a better understanding of the potential impacts of infrastructure development and logistics regulations in Saudi Arabia as they look to expand and strengthen the country's freight network while reducing fuel consumption and greenhouse (GHG) emissions. In this context, it showcases how transport policies can substantively affect freight activities and illustrates the effectiveness of financial measures, such as fuel subsidy reductions and environmental taxes that channel revenue back to infrastructure or other transport initiatives.

Utilizing the KAPSARC Transport Analysis Framework (KTAF), a tool for estimating freight transport activity and the impact of transport policy based on open-source data, this study considers the heterogeneity of urban, regional and inter-regional localities in the Kingdom in terms of their socioeconomic and spatial differences. Based on these results, the paper then reviews a selection of the most commonly cited urban freight transport policies. These policies were analyzed by the European Commission (EC) Joint Research Center's Institute for Prospective and Technological Studies (IPTS) as part of the development of sustainable urban mobility plans in Europe (Lopez-Ruiz et al. 2013). The IPTS report measures aim to reduce transport externalities, specifically those linked to GHG and air pollutants in city cores. Additionally, the study estimates the expected fuel savings that would result from the policies in question. The IPTS report quantifies the impacts of policy measures according to city type and transport network. This approach is used in this paper to find relevant policy measures for Saudi Arabia and adapt them to suit its city types.

KTAF methodology infers economic and human activity data by combining nighttime lights (NTL) satellite images and economic indicators of employment and employment productivity. It then analyzes these results with an aggregate four-step transport demand model. Finally, it assesses the impact of different policy measures by applying an avoid-shift-improve (A-S-I) framework.

The study evaluates two scenarios for Saudi Arabia from 2020 to 2030. The first examines the impact of the Landbridge project, which will join the Kingdom's Eastern Province and Makkah Province with a modern freight rail connection, causing a modal shift from road to rail transport. The second builds on this by adding regulatory measures to help fund the infrastructure buildout and deter the environmental externalities of road transport by returning their costs to the logistics industry. 
The analysis examines the urban centers of Saudi Arabia's 13 provinces. For each of these city clusters, it creates a profile by assessing transport activity, population, urbanization rates, economic activity, and transportation network connectivity. The study then applies a specific spatial weight to each province to account for the effects of transport policies, according to the respective profiles of these urban areas. The Appendix details this methodology.

Before continuing to the quantitative analysis, it is helpful to review the basic characteristics of freight transport in Saudi Arabia. The Kingdom relies heavily on its road network, which extends over 68,000 kilometers $(\mathrm{km})$, compared with just 4,175 $\mathrm{km}$ of freight rail. Multi-modal transport is limited and just two important freight railways exist in the country. One connects the main dry hub in Riyadh to the commercial port of Dammam in the east; the other runs between Riyadh and the northeastern mineral deposits. Diesel fuel powers virtually all road and rail freight logistics in Saudi Arabia. Maritime transport is another key means of freight shipment in the Kingdom. Currently, the country has nine public ports, of which seven are commercial and two are industrial, as well as one private freight port. 
KTAF methodology integrates five analytic steps into an online network analysis visual application (Figure 1). First, it combines NTL satellite images with indicators of employment and employment productivity to infer economic and human activity data, segregated for the purposes of this study by different profiles of urban centers. Second, it analyzes this data in an aggregate four-step transport demand model. Third, KTAF employs an approach known as ASIF (activity, modal share, energy intensity, carbon intensity of fuel), initially developed by Schipper et al. (2001), to estimate energy consumed and emissions from transport. Fourth, it applies an avoid, shift, and/or improve approach (A-S-I) approach for setting policy measures. This approach focuses on demand-side policy measures that create sustainable transport system design. It focuses on reducing the use of high-emitting transport modes, shifting toward more environmentally friendly modes and optimizing the operational and technological efficiency of transport modes (Bongardt et al. 2019). Finally, KTAF conducts an impact assessment of the environmental, economic and social outcomes of freight movement. (Note: this study does not currently apply this step). KTAF displays the results in an online network analysis visual application that provides policymakers with a simulation of the effects of transport policy measures.

The following sections describe the above methodology in detail.

\section{Data acquisition}

KTAF acquires data by estimating total freight transport activity utilizing freely available economic indicators and NTL satellite images to infer economic and human activity. Specifically, it uses satellite radiometry to estimate total freight transportation activity in a given area based on the intensity of NTL as they relate to economic and human activity on the ground. This methodology reflects an established body of work in other research areas that derive data from NTL satellite images. KTAF applies the foundation of this methodology to the freight transport sector, as described in Lopez-Ruiz, Nezamuddin, Al Hassan, and Muhsen (2019), "Estimating Freight Transport Activity Using Nighttime Lights Satellite Data in China, India and Saudi Arabia."

Figure 1. KTAF Methodology.

\section{General methodology (freight and passenger)}

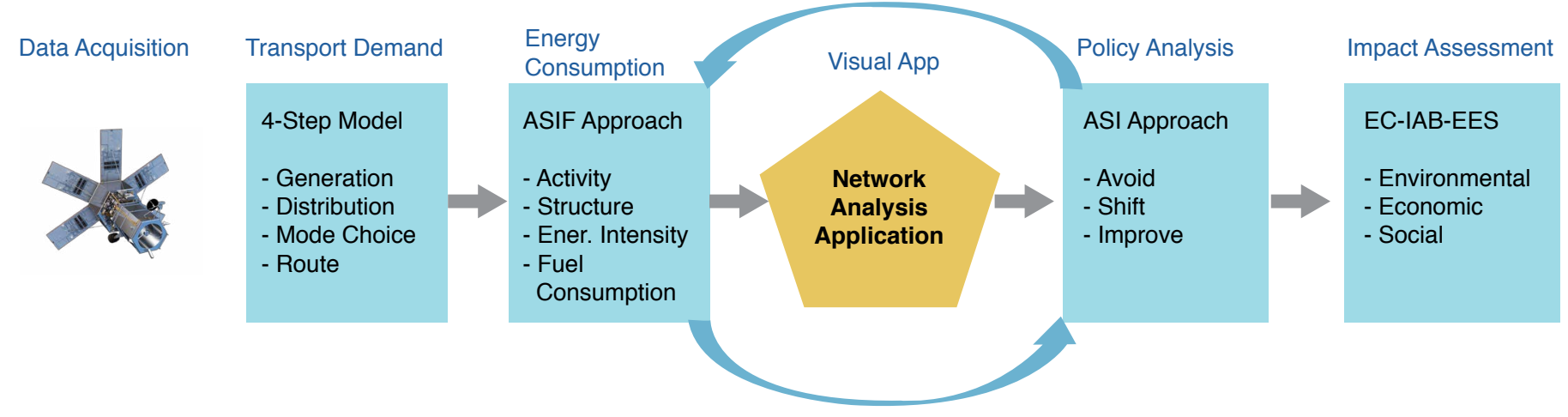

Source: KAPSARC. 
The employment data used in this analysis is taken from the annual Saudi General Statistics Authority surveys from 2012 to 2017 . Transport activity between provinces was estimated from province-level consumption and production data. A detailed description of the methodology used in this paper can be found in Lopez-Ruiz et al. (2019).

\section{Transport demand model}

Using the economic and human activity data found above, the study applies the standard aggregate four-step transport model, which usually looks at generation, distribution, mode choice and routing. However, KTAF analysis derives only generation and distribution. The former aims to determine the incoming and outgoing goods from the totality of land freight movement. It divides generation of demand data into primary (extraction of raw materials), secondary (manufacturing) and tertiary (services and intangibles) sector freight activity, permitting the creation of origin-destination (O-D) vector totals. The distribution component of the model utilizes total O-D vectors to estimate the O-D matrix using a proportional fitting approach (Ortúzar and Willumsen 2011).

\section{Measuring policy impacts on transportation energy consumption}

Next, the study creates city profiles that facilitate the analysis of policy effects on each specific region. These are based on the IPTS methodology that employs the results of five international studies to

Figure 2. City-region classification.

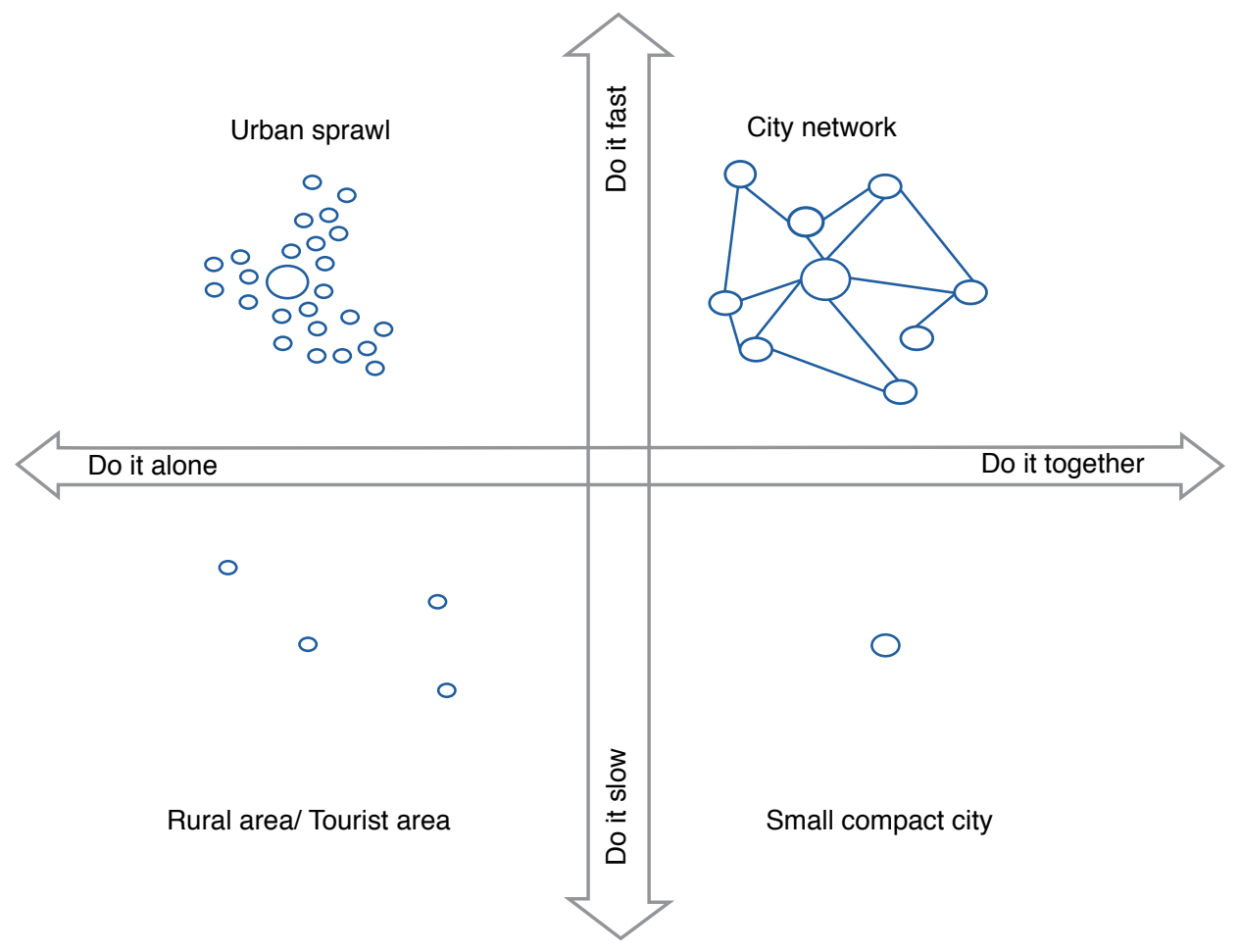

Source: PASHMINA project, D.2.1 p.2, 2011. 
develop a scorecard for the evaluation of policy impact (IPTS 2013). The profiles are then applied to four distinct region-types: city networks, urban sprawl, small-sized compact cities and medium-sized compact cities. Figure 2 above showcases the categorization developed by the Paradigm Shifts Modelling and Innovation Approaches (PASHMINA) project to classify different city-profiles according to their transportation, connectivity, size characteristics. The KTAF methodology applies the PASHMINA framework to calculate the potential effects of sustainable transport measures in relation to the intrinsic functions of different types of transport networks in various cities.

Currently, diesel-powered vehicles provide nearly all freight transport in the country with limited competing modes of distribution available. Defining profiles for specific urban zones in Saudi Arabia's different regions allows the differentiation of policy impact assessment based on city structure. This approach aims to account for performance differentials between cities to deliver a realistic impact assessment, based on estimates of transit speed, connectivity and overall geographical accessibility.

The study defines the urban profiles by assessing the particular characteristics of cities by population density (per square km), connectivity and intensity of economic and human activity. Connectivity is measured using Open Street Maps crowd-sourced data on road infrastructure. Intensity of economic and human activity is estimated based on GDP per capita and utilization of the NTL-derived data (Lopez-Ruiz et al., 2019). For more detail on the analysis, please see the Appendix.

Next, the study develops a categorization of city typologies to differentiate the overall characteristics of each province in Saudi Arabia (Appendix). The results of this analysis, presented as intervals of fuel saved, indicate the potential impact of applying the identified policy measures across all regions of the study.

The scores from different sources for individualized policy measures were taken from the IPTS report, which categorized them into a single scoring template A-S-I approach, as developed by the German Development Agency (GIZ) in 2011. Specifically, this methodology looks at how to "avoid" and/or reduce trips, "shift" to more environmentally friendly modes and "improve" (i.e., reduce) the energy intensity of transport activities through technological and/or behavioral changes.

\section{Forecasting}

The KTAF visual application analyzes policy impacts, with 2012 as the baseline year. The data used for the training of the statistical forecast model defines sectoral employment totals and employment productivity as explanatory variables for total freight transport activity at a regional level. The statistical analysis was carried out using the MATLAB machine learning suite.

The study employs an exponential Gaussian process regression (GPR) approach to forecast the results as the best fit with regards to the data. GPR is a stochastic process that finds a distribution over the possible functions and is consistent with observed data.

Table 1 above shows the results of the exponential GPR test conducted to check the data for statistical significance. For the 105 observations in the statistical analysis, it found $\mathrm{R}$ squared of 0.94 and root-mean-square error of 0.14263 . 
Table 1. Exponential Gaussian process regression for Saudi Arabia.

$\begin{array}{ll}\text { Results } & \\ \text { RMSE } & 0.14263 \\ \text { R-Squared } & 0.94 \\ \text { MSE } & 0.020343 \\ \text { MAE } & 0.10003 \\ \text { Prediction speed } & \sim 8600 \mathrm{obs} / \mathrm{sec} \\ \text { Training time } & 0.2651 \mathrm{sec}\end{array}$

Model Type

Preset: Exponential GPR

Basis function: Constant

Kernel function: Exponential

Use isotropic kernel: true

Kernel scale: Automatic

Kernel signa: Automatic

Sigma: Automatic

Standardize: true

Optimize numeric parameters: true

\section{Feature Selection}

All features used in the model, before PCA

Figure 3. True versus predicted results for Saudi Arabia, 2012 - 2017.
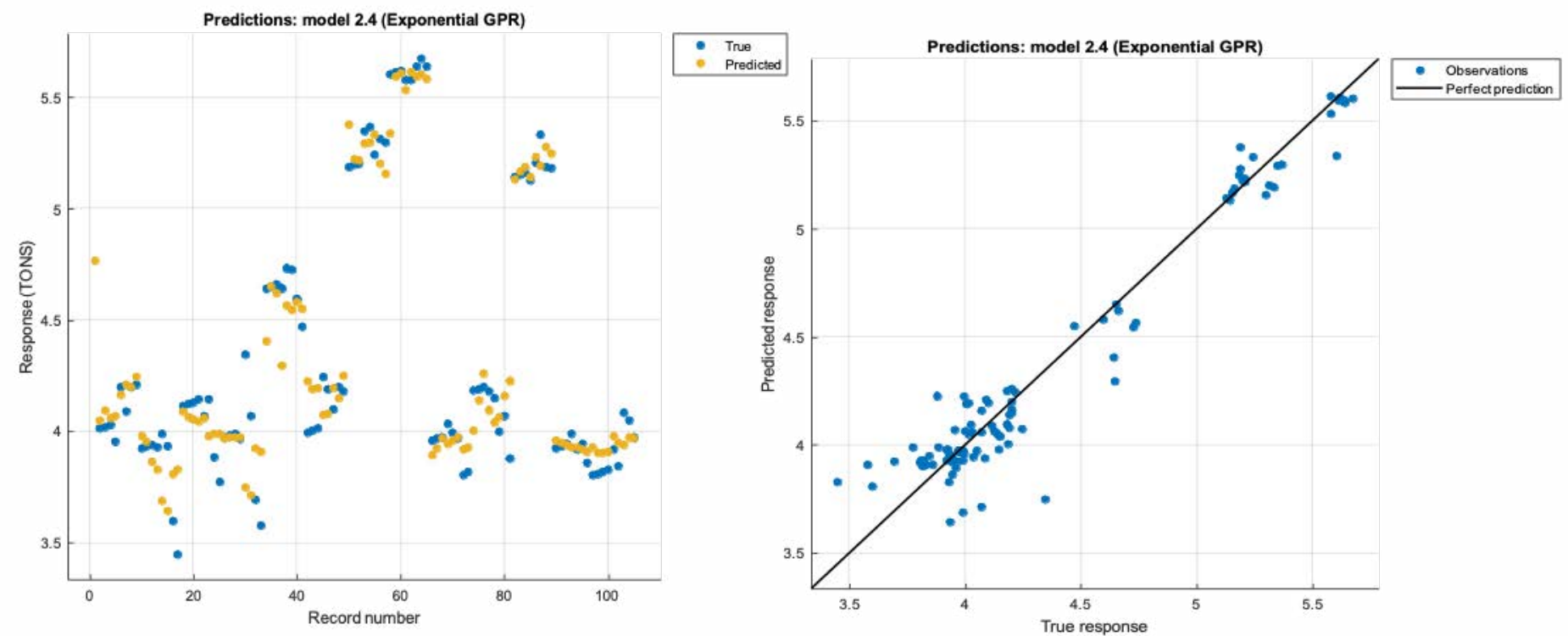

Source: KAPSARC analysis. 
The statistical model can then forecast transportation demand for all provinces of Saudi Arabia. The explanatory variables to 2030 on employment and employment productivity were derived from the long-term baseline projections by the OECD and integrated into the econometric model. This allows for the definition of transport demand totals to 2030 by origin and destination to all provinces. Figure 3 above depicts the relationship between the true versus predicted results of the statistical analysis for Saudi Arabia from 2012 - 2017, indicating a high degree of fit of the statistical model to the observed data. 


\section{Scenarios for Saudi Arabia}

\section{Scenario 1: Infrastructure measures}

The first scenario looks at the impact of infrastructure development on freight movement in Saudi Arabia. Specifically, it evaluates how the construction of the Landbridge, the planned railway from Makkah Province to Riyadh Province and linking to the existing Eastern Province railway, would change fuel consumption in the country by 2030 .

In 2017, the total freight tonnage transported by land between Riyadh and Makkah provinces was 86.62 million metric tonnes (MMmt). This represents an estimated $25 \%$ of the total overland transport (excluding imports and exports) between Makkah Province and Riyadh Province. Based on this percentage, and given that in 2017, container throughput for all Red Sea ports in Makkah Province totaled $45 \mathrm{MMmt}$ (of $889 \mathrm{MMmt}$ for seaborne trade for all Saudi Arabia), 11.16 MMmt is a good estimation of the freight volume for imports and exports between the Red Sea and Riyadh Province. Currently, this route relies solely on road transport, which primarily consumes diesel fuel.

By contrast, rail transport carries $80 \%$ of the container freight volume transported between Dammam and Riyadh. This percentage provides a working assumption for the volume of containerized goods that would be carried by the Landbridge between Riyadh and Makkah Province. This translates to the movement of 8.64 million tonnes by rail between Riyadh and Makkah, equal to a modal shift from road to rail of around $11 \%$. This reduces fuel consumption for freight transportation by about $13 \%$ by 2030 , assuming the Landbridge comes into effect in 2020 (Table 2).

Table 2. Results of fuel consumption policies in barrels of oil equivalent (BOE) in 2030.

\begin{tabular}{l|c|c} 
& Total fuel consumption (BOE) in 2030 & Percent change between scenarios \\
\hline Baseline scenario & $87,445,176$ & $-2 \%$ \\
\hline Fuel tax effect & $85,734,539$ & $-3 \%$ \\
\hline Environmental tax effect & $85,235,603$ & $-13 \%$ \\
\hline Modal shift effect (Landbridge) & $76,441,076$ & $-17 \%$
\end{tabular}

Source: KAPSARC Transport Analysis Framework. 
Based on the average cost of railway construction in Saudi Arabia of 11 million US\$ per rail-kilometer, the Landbridge will cost around US\$11 billion. This estimate aligns with the rail unit costs found in a study by Baumgartner (2001). Therefore, each US $\$ 1$ billion of investment in rail infrastructure between Riyadh and Makkah provinces would translate to a little over $1 \%$ in reduced fuel consumption. Over a 50-year lifespan, this means the investment in rail infrastructure required to shift one tonne of road freight to rail is US\$25 (excluding rolling stock, operating costs and other expenses). This reduction in fuel consumption represents less than $1 \%$ of the pledged Paris Agreement targets for Saudi Arabia, which is a reduction of up to 130 million tonnes of $\mathrm{CO}_{2}$ equivalent by 2030 (Climate Action Tracker 2019).

However, this calculation does not take into account that the Landbridge would effectively connect to the Gulf Cooperation Council (GCC) railway through Dammam, encouraging greater use of the former. Moreover, it does not include the possibility of reinforcing the Landbridge's effect on increasing energy efficiency in freight transport activities through a mix of policy measures.

\section{Scenario 2: Combining regulatory measures with infrastructure development}

The second scenario looks at combining infrastructure development with regulations that incentivize increased freight transport efficiency. This can reduce the burden of infrastructure expenses on the government and add a revenue stream from environmental taxes. Specifically, the study applies two policies: a price reform that benchmarks diesel closer to international prices and a charge that aims at better internalizing the negative externalities linked to the use of road transportation for freight activities. The model implements these regulations from 2020, reinforcing the modal shift from road to rail transport by increasing the relative attractiveness of the latter. Note that Scenario 2 assumes no subsidies for rail, given that the government of Saudi Arabia has expressed its goal of linking domestic diesel fuel prices with international benchmarks by 2023 .

Table 3. Range of savings for Scenario 2.

\begin{tabular}{l|l}
\hline Fuel savings [at international distribution prices] & Yearly \\
\hline Diesel fuel reform revenue in 2030 & {$[$ US\$ $1.067-1.255$ billion] } \\
\hline Environmental charge revenue in 2030 & {$[$ US\$ $222-370$ million] } \\
\hline Total revenue stream & {$[$ US\$ 285- 404 million] } \\
\hline Total increase of diesel fuel charge in 2030 & {$[$ US\$ $1.574-2.030$ billion] } \\
\hline Total increase of environmental charges in 2030 & {$[13 \%-22 \%]$} \\
\hline Combined average applied charges growth per year (2020-2030) & {$[17 \%-28 \%]$} \\
\hline
\end{tabular}

Source: KAPSARC Transport Analysis Framework. 
In the second scenario, the analysis applies the price elasticity of fuel as estimated by Atalla, Gasim, and Hunt (2017) as the basis for calculating the impact ranges for diesel fuel reform, environmental charges on diesel and fuel savings. The effect is measured as the estimation of the expected additional revenue stream from the implementation of these policy measures (Table 3). This additional revenue stream is consistent with an increase in diesel fuel charges from 2020 to 2030 of between $13 \%$ and $22 \%$ and a rise in environmental charges by 2030 in the range of $17 \%$ to $28 \%$. The revenue from diesel fuel reform and environmental charges implemented in the second scenario totals over US $\$ 1$ billion by 2030 . This includes an average revenue of US\$296 million from diesel fuel reform and US\$344 million from environmental charges. Although these regulations would increase transportation prices in Saudi Arabia, they would also help finance rail infrastructure and establish a rail user-tariff structure under which rail freight would be charged solely for operation and maintenance costs. This would possibly increase the efficiency of Saudi Arabia's rail sector.

The combination of infrastructure development and regulatory measures in Scenario 2 reduces fuel consumption by $17 \%$ from the annual baseline (business-as-usual scenario). This translates to a fall from 87 million barrels of oil equivalent (BOE) in 2030 to 72.5 million BOE in 2030 (under this particular scenario). This fall is about $4 \%$ greater than under the infrastructure policies alone. Regarding environmental impact, the policy measures applied imply a reduction of $\mathrm{CO}_{2}$ emissions of around 19\% between 2020 and 2030 , including the vehicle technology changes expected to occur. This adds to the reductions solely explained by the modal shift effect. 


\section{Conclusions}

audi Arabia's transport sector can play an important role in facilitating the country's efforts to diversify its economy. This study offers empirical insights into infrastructure and logistics policies in Saudi Arabia, building on the EU Commission's urban/region profile typologies approach to quantify the impacts of transport regulations.

Using the IPTS methodology as a benchmark, this study applies the KAPSARC Transport Analysis Framework (KTAF) methodology, which involves five steps. The process begins by inferring economic and human activity data by combining NTL satellite images and economic indicators of employment and employment productivity. Next, KTAF analyzes this data with an aggregate four-step transport demand model, and then applies an ASIF approach to these results. Finally, it utilizes an A-S-I approach to setting policy measures. KTAF visually portrays the final output of the analysis in an online application, providing policymakers with an easily digestible representation of the transport policy simulation.

The analysis considers two scenarios for Saudi Arabia, both applied from 2020. Scenario 1 looks at the effects of developing the Landbridge, the planned railway project connecting Makkah Province to the Eastern Province through Riyadh. The Red Sea ports of Saudi Arabia handle around $50 \%$ of the throughput of containerized goods in the country, and the tonnes moved between Riyadh Province and the Red Sea ports make up 25\% of that total. This scenario results in an $11 \%$ modal shift from road to rail transport and in turn, a $13 \%$ reduction in diesel fuel consumption by 2030 .

Scenario 2 combines the Landbridge infrastructure development with regulations to reduce fuel consumption: diesel fuel price reform and environmental charges. These policies aim to deter fuel consumption and generate an additional revenue stream to help cover the cost of infrastructure developments such as the Landbridge. Under Scenario 2, the total revenue stream (comprising diesel fuel price reform, environmental charges and fuel savings) is around US $\$ 1$ billion. This allows Saudi Arabia to achieve an aggregate $17 \%$ reduction in fuel consumption (also taking into account expected vehicle technology efficiencies during 2020 - 2030) and an estimated 19\% drop in Saudi Arabia's $\mathrm{CO}_{2}$ emissions by 2030 .

Finally, the results demonstrate the considerable impact infrastructure development and transport policy measures can have on fuel consumption in freight activities in Saudi Arabia. The study showcases the potency of combining different policy approaches to increase the efficiency of freight transport activities, reduce emissions of GHG and other pollutants, and decrease fuel consumption in freight transport activities while developing critical transport infrastructure that can help the Kingdom meet its 2030 economic reform targets.

However, given that the Landbridge would connect Makkah Province to the Eastern Province through Riyadh, the development raises the question of whether Saudi Arabia should differentiate domestic freight rail from international GCC tonnages moved through the country. In the future, it may be profitable and congestion-alleviating to introduce a 'Saudi vignette' system based on Switzerland's approach to levying fees on foreign transit operators to cover the expenses of using Swiss infrastructure. 


\section{References}

Akkermans, Lars, Kris Vanherle, Alessandra Moizo, Paola Raganato, Burkhard Schade, Guillaume Leduc, Tobias Wiesenthal, Simon Shepherd, Miles Tight, Astrid Guehnemann, Michael Krail, and Wolfgang Schade. 2010. "Deliverable 2.1 - Ranking of measures to reduce GHG emissions of transport: reduction potentials and feasibility qualification." GHG-TransPoRD. https://www. ghg-transpord.eu/ghg-transpord.eu/ghg-transpord/ downloads/GHG_TransPoRD_D2_1_GHG_reduction_ potentials.pdf

Atalla, Tarek N., Anwar A. Gasim, and Lester C. Hunt. 2018. "Gasoline Demand, Pricing Policy and Social Welfare in Saudi Arabia: A Quantitative Analysis." Energy Policy 114(3): 123-133. https://doi.org/10.1016/j. enpol.2017.11.047

Banister, David, Robin Hickman, and Dominic Stead. 2007. "Looking over the Horizon: Visioning and Backcasting." In Building Blocks for Sustainable Transport, edited by A. Perrels, V. Himanen, and M. Lee-Gosselin, 25-53. Bingley, United Kingdom: Emerald Group Publishing Limited. https://doi. org/10.1108/9780857245168-003

Banister, David, Dominic Stead, Peter Steen, Jonas Åkerman, Karl Dreborg, Peter Nijkamp, and Ruggero Schleicher-Tappeser. 2000. European Transport Policy and Sustainable Mobility. London: E \& FN Spoon.

Baumgartner, J.P. 2001. "Prices and Cost in the Railway Sector." Ecole Polytechnique Federale de Lausanne. https://www.cupt.gov.pl/images/zakladki/ analiza_koszt\%C3\%B3w_i_korzysci/J_P_Baumgartner_ Prices_and_Costs_in_the_Railway_Sector_Ecole_ Polytechnique_Federale_de_Lausanne_2001.pdf

Bongardt, Daniel, Lena Stiller, Anthea Swart, and Armin Wagner. 2019. "Sustainable Urban Transport: Avoid-ShiftImprove (A-S-I)". Deutsche Gesellschaft fur Internationale Zusammenarbeit (GIZ) GmbH. https://sutp.org/files/ contents/documents/resources/L_iNUA/ASI_TUMI_ SUTP_iNUA_April\%202019.pdf

Climate Action Tracker. Accessed December 31, 2019. https://climateactiontracker.org/countries/saudi-arabia/
International Energy Agency (IEA). 2019.

"Tracking Transport." https://www.iea.org/reports/ tracking-transport-2019

KonSULT. n.d. The University of Leeds. http://www. konsult.leeds.ac.uk/

Lopez-Ruiz, Hector. G., Panayotis Christidis, Hande Demirel, and Mert Kompil. 2013. "Quantifying the Effects of Sustainable Urban Mobility Plans." European Commission, Joint Research Centre, Institute for Prospective and Technology Studies (IPTS).

Lopez-Ruiz, Hector G., Nora N. Nezamuddin, Reema AI Hassan, and Abdel Rahman Muhsen. 2019. "Estimating Freight Transport Activity Using Nighttime Lights Satellite Data in China, India and Saudi Arabia." KAPSARC DOI:10.30573/KS--2019-MP07.

National Oceanic and Atmospheric Administration (NOAA). 2018. Version 1 VIIRS Day/Night Band Nighttime Lights. https://ngdc.noaa.gov.

OECD. 2018. "OECD Economic Outlook." No 103, July. Accessed February 12, 2019. https://stats.oecd.org/ Index.aspx?DataSetCode=EO103_LTBOE

Ortúzar, Juan de Dios, and Luis G. Willumsen. 2011. Modelling Transport. 4th Edition, Hoboken: Wiley. http:// dx.doi.org/10.1002/9781119993308

Paradigm Shifts Modelling and Innovation Approaches (PASHMINA) Project. 2011. http://www.pashmina-project. eu

Schipper, Lee, and Celine Marie-Lilliu. 1999.

"Transportation and CO2 Emissions: Flexing the Link - A Path for the World Bank." Environmentally and Socially Sustainable Development. The World Bank. Paper No. 69.

Victoria Transport Policy Institute (VTPI). Transport Demand Management Encyclopedia. https://www.vtpi. org/tdm/index.php

European Platform on Mobility Management.

www.epomm.eu. 


\section{Appendix}

This regionalization is conducted using Grouping Analysis, a geo-processing clustering process that groups features based on attributes and spatial constraints. The tool finds spatially contiguous clusters of features based on specified attributes and cluster size limits. Such analysis is particularly valuable in transport assessments because it can quantify the connectivity and accessibility of economic hubs.

The process consists of creating a feature class in which the original input data is transformed into clusters that present the lowest possible variance within a given cluster and the maximum possible variability between clusters.

This study uses the multi-polygon cluster layer to assess infrastructural accessibility and connectivity for different activity hubs in Saudi Arabia. This identifies the level of connectivity and accessibility for different zones in Saudi Arabia.

For this, the Open Street Map (OSM) API is employed to download road networks for the 300 areas created with the Grouping Analysis. This information is then used to compute the connectivity matrix for each one of those 300 zones. This project does not attempt to offer insight on possible infrastructural optimizations and intends only to assess the present functioning of the transportation network to infer the possible impact of different policy measures based on existing transport infrastructure and urban configurations.

Example of connectivity processing:

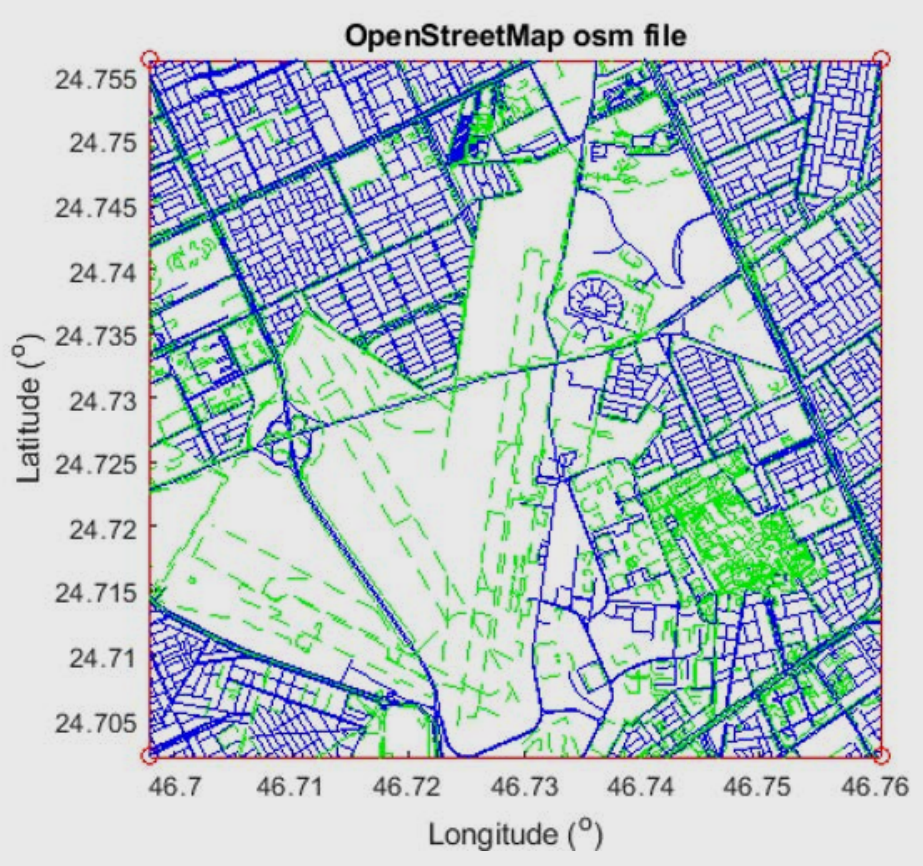

Source: Open Street Map. 
The connectivity scoring obtained from the OSM data for each cluster is then aggregated and averaged to establish corresponding scores for each province in Saudi Arabia. Each province is also given an economic and human activity index value based on the nighttime light (NTL) intensity of the zone, utilizing day and night band information acquired with the Visible Infrared Imaging Radiometer Suite, based on the approach detailed in Lopez-Ruiz et al. (2019).

Detailed indicators for 13 Saudi provinces:

\begin{tabular}{|c|c|c|c|c|c|}
\hline Province & $\begin{array}{l}\text { Average road } \\
\text { connectivity }\end{array}$ & $\begin{array}{l}\text { Average } \\
\text { typology }\end{array}$ & Population & $\begin{array}{l}\text { Economic and } \\
\text { human activity } \\
\text { index }\end{array}$ & $\begin{array}{c}\text { Density of } \\
\text { inhabited area } \\
(1,000 \text { per sq. } \mathrm{km})\end{array}$ \\
\hline Ar Riyad & 2.7 & 1 & $8,002,100$ & 8.75 & 1.59 \\
\hline Makkah & 2.8 & 2 & $8,325,304$ & 5.27 & 0.93 \\
\hline Ash Sharqiyah & 2.1 & 4 & $4,780,619$ & 2.47 & 2.05 \\
\hline Al Madinah & 2.3 & 2 & $2,080,436$ & 2.38 & 1.18 \\
\hline AI Quassim & 1.0 & 4 & $1,387,996$ & 8.62 & 3.46 \\
\hline Ha'il & 1.7 & 3 & 684,619 & 3.35 & 1.87 \\
\hline Asir & 2.2 & 4 & $2,164,172$ & 1.28 & 1.90 \\
\hline Jizan & 2.0 & 3 & $1,533,680$ & 1.94 & 3.88 \\
\hline Tabuk & 2.8 & 3 & 890,922 & 1.17 & 0.95 \\
\hline Najran & 2.2 & 3 & 569,332 & 1.33 & 4.76 \\
\hline Al Jawf & 1.5 & 3 & 497,509 & 1.20 & 4.62 \\
\hline $\begin{array}{l}\text { Al Hudud ash } \\
\text { Shamaliyah }\end{array}$ & 2.0 & 3 & 359,235 & 0.69 & 3.41 \\
\hline
\end{tabular}

Sources: KAPSARC and OSM. 
Notes

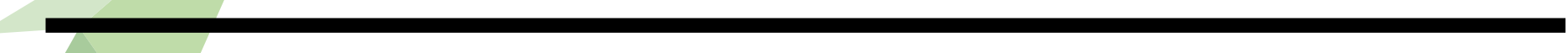




\section{Notes}

(1) 


\section{About the Authors}

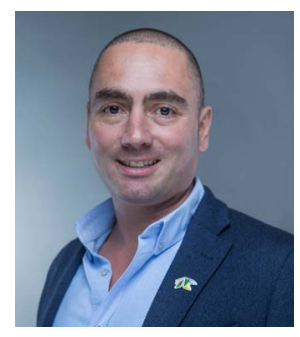

\section{Hector Lopez-Ruiz}

Hector is a research fellow specializing in transportation economics.

He holds a Ph.D. in Economics from the University of Lyon.

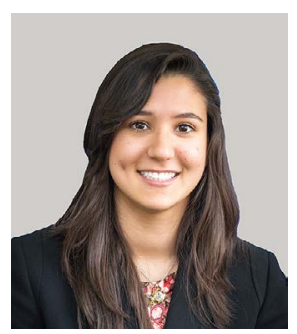

\section{Nora Nezamuddin}

Nora is a research associate focusing on transport economics, policy and modeling. She holds an M.Sc. in Maritime and Air Transport Management from the University of Antwerp in Belgium and a B.Sc. and B.A. in Business Administration and International Relations from The American University in Washington, D.C.

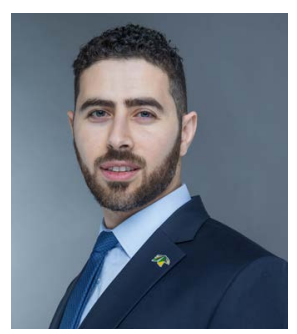

\section{Abdel-Rahman Muhsen}

Abdel-Rahman is a research associate and a certified GIS Professional (GISP). He holds an M.Sc. in Geomatics Engineering from the University of Calgary, Canada. His research interests focus on transportation, spatial analytics and geo-information management.

\section{About the Project}

The Kingdom of Saudi Arabia wants to become a global logistical hub by developing its transportation infrastructure to further its economic diversification. This is one of the main priorities for policymakers as stated in their National Transformation Initiatives and the KSA Logistic Hub plan. The KAPSARC Transport Analysis Framework (KTAF) aims to assess the current status and future of freight transportation in the Kingdom from global and local perspectives. It aims to do this first by establishing a baseline of the current global freight network, second by assessing possible futures in order to meet different policy objectives. Finally, it is building scenarios of the costs, benefits and risks associated with freight development. 
INAPSARC

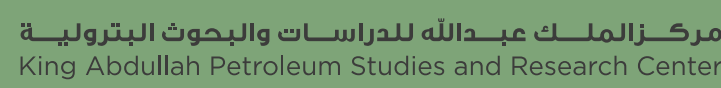

www.kapsarc.org 